The Call for Papers and Calendar sections list conferences, symposia, and workshops that are of potential interest to AMS members. Complete information about events listed in the calendar can be found on the meetings page of the AMS website, www.ametsoc.org. New additions to the calendar are highlighted.

To list an event in the calendar, please submit the event name, dates, location, and deadlines for abstracts, manuscripts, and preregistration to amsmtgs@ametsoc.org. For a submission to appear in a given issue, it must be submitted at least eight weeks prior to the month of publication (that is, to appear in the March Bulletin, the submission must be received by I January).

\section{AMS MEETINGS}

\section{9}

\section{MARCH}

2019 Washington Forum, 27-29

March, Washington, D.C.

\section{MAY}

15th Conference on Polar Meteorology and Oceanography, 19-23 May, Boulder, Colorado

Session topic proposal deadline: TBD

Abstract deadline: 18 January 2019

Preregistration deadline: 19 April 2019

Extended abstract deadline: 21 June 2019

Initial announcement published: Aug. 2018

\section{JUNE}

47th AMS Conference on Broadcast Meteorology/Fifth Conference on Weather Warnings and Communication, 12-14 June, San Diego, California

Session topic proposal deadline: TBD

Abstract deadline: 13 February 2019

Preregistration deadline: 8 May 2019

Extended abstract deadline: 12 July 2019

Initial announcement published: Nov. 2018

22nd Conference on Atmospheric and Oceanic Fluid Dynamics, 24-28 June, Portland, Maine

Abstract deadline: 25 February 2019

Preregistration deadline: 22 April 2019

Extended abstract deadline: 26 July 2019

Initial announcement published: Nov. 2018

\section{JULY}

18th Conference on Mesoscale Processes, 29 July-1 August, Savannah, Georgia

Abstract deadline: 25 March 2019

Preregistration deadline: 14 June 2019

Extended abstract deadline: 28 June 2019

Initial announcement published: Sep. 2018

\section{SEPTEMBER}

39th International Conference on Radar Meteorology, 16-20 September, Nara Kasugano International Forum, Nara, Japan

Abstract deadline: 20 May 2019

Preregistration deadline: 1 August 2019

Extended abstract deadline 16 August 2019

Initial announcement published: Oct. 2018

\title{
STUDENT TRAVEL GRANTS
}

Student Travel Grants are available for senior undergraduate and graduate students to attend AMS meetings held in the United States and Canada. The travel grants are available only to members, including student members, of the AMS.

AMS recognizes the considerable benefit that students can gain from attending conferences even if they are not presenting a paper there, and AMS wants to encourage interactions between students and other conference attendees. To this end, travel grants will be awarded to a student who is not presenting a paper at the conference.

Students who are presenting papers and potentially in need of travel support should inquire of the program chair whether any funds will be available for this purpose.

For more information and to complete an application form, please visit the AMS website at www.ametsoc.org. 
23rd AMS Satellite Meteorology, Oceanography and Climatology Conference/2019 EUMETSAT Meteorological Satellite Conference/NOAA Satellite Conference, 28 September-4 October, Boston, Massachusetts Session topic proposal deadline: TBD Abstract deadline: 8 April 2019

Preregistration deadline: 2 August 2019

Extended abstract deadline: 8 Nov. 2019

Initial announcement published: Aug. 2018

\section{MEETINGS OF INTEREST}

\section{9}

\section{FEBRUARY}

Oceanology International America, 25-27 February, San Diego, California

\section{MARCH}

A\&WMA Eighth Specialty Conference on Air Quality Models, 19-21 March, Durham, North Carolina
APRIL

\section{OCTOBER}

AUVSI XPONENTIAL 2019, 29 April-2 May, Chicago, Illinois

\section{JUNE}

17th Annual Climate Prediction Applications Science Workshop (CPASW), 11-13 June, Charleston, South Carolina

AMOS Annual Meeting 2019 and the International Conference on Tropical Meteorology and Oceanography, 11-15 June, Darwin, Australia

The Sixth International Symposium on Atmospheric Light Scattering and Remote Sensing (ISALSaRS), 17-21 June, Hangzhou, China

\section{SEPTEMBER}

35th International Conference on Alpine Meteorology (ICAM), 2-6 September, Riva del Garda, Italy
Mathematics of the Weather 2019, 14-16 October, Bad Orb, Germany

15th International Conference on Atmospheric Sciences and Applications to Air Quality MY, 28-30 October, Kuala Lumpur, Malaysia

\section{NOVEMBER}

Fourth COSPAR Symposium, 4-8 November, Herzliya, Italy

\section{0}

\section{AUGUST}

43rd COSPAR Scientific Assembly and Associated Events, 15-23 August, Sydney, Australia

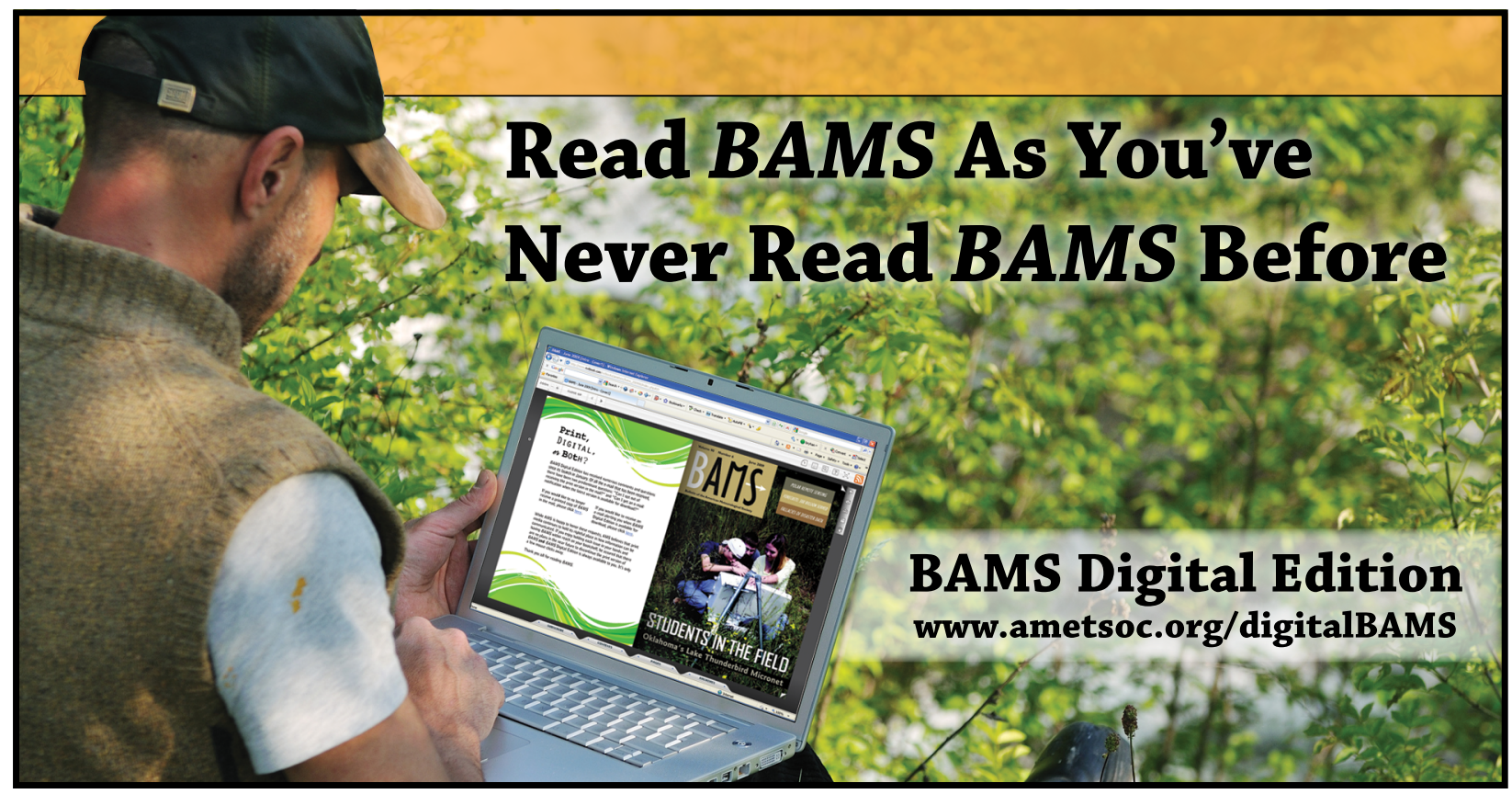


Find out from the authoritative source

[ What's a dust devil? ]

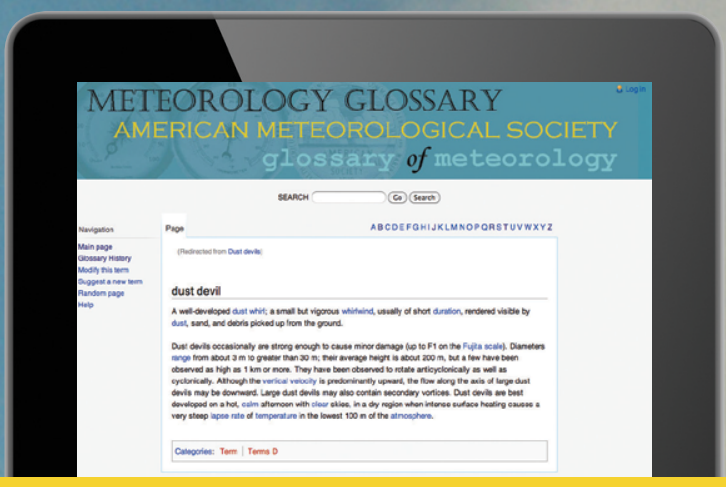

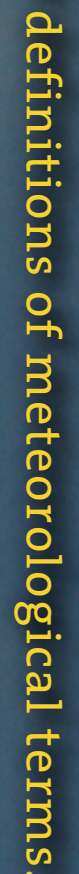

THE AMERICAN METEOROLOQICAL SOCIETY

\section{Online Glossary of Meteorology}

With over 12,000 meteorological terms, you'll be able to look up definitions online any time, any place, anywhere.

http://glossary.ametsoc.org/wiki

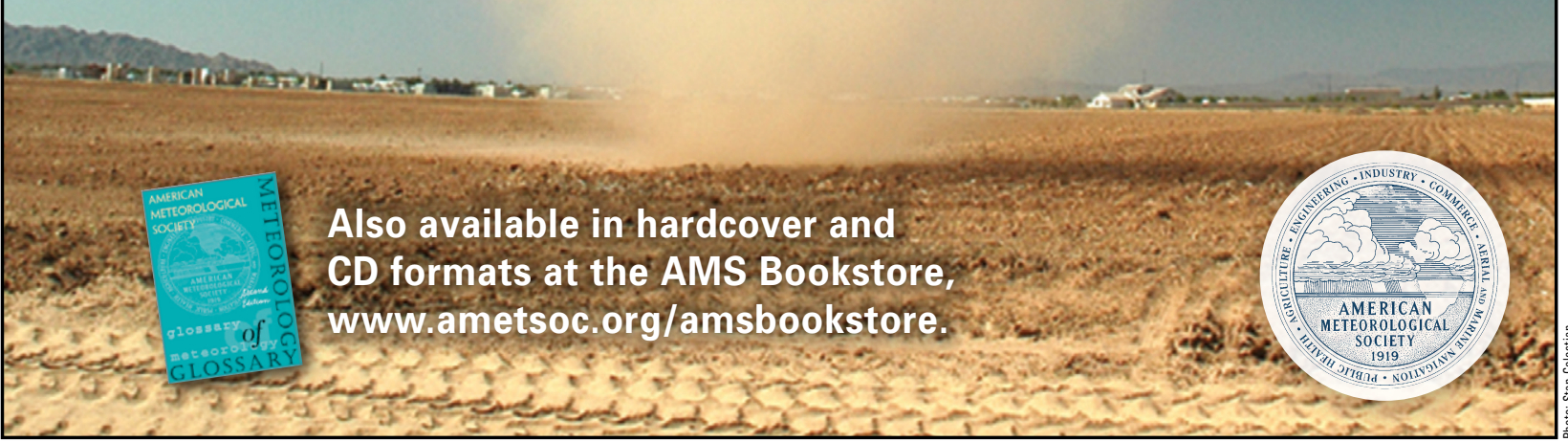

